\title{
The Enlightenment of Children's Language Learning Mechanism on Adult Foreign Language Learning
}

\author{
Siren Ren \\ Beijing No.80 middle school, Qinhuangdao, Hebei, 066000, China \\ Corresponding author. Email: gaoming@cas-harbour.org

\begin{abstract}
Children learn their mother language very quickly and effortless, while foreign language learning is extremely difficult for adults, spending more time, but very effective.This paper analyzed the same and different points between them by comparison.Hopefully, some inspiration to help adults learn foreign languages.
\end{abstract}

Keywords: Language learning mechanism, Language formation, Language learning in adults, Patterns of language learning, Behaviorist theory

\section{INTRODUCTION}

Children learn language is very fast, children learn language is relaxed and pleasant, compared to adults to learn a second language is very difficult. Therefore, why is the effect of children learning language so much differently? This research will be studied from language formation in children as well as language learning in adults. The emphasis is on the way children acquire language and the analytical study of the patterns of adults learning foreign languages.

\section{BEHAVIORIST THEORY AND COGNITIVE THEORY}

Psycholinguistics There are two main theories on language acquisition: one is behaviorism theory, and the other is cognitive theory. The representative figure of the behaviorist theory is the behaviorist psychologist F.B.Skinner. He believes that language learning is not a thinking process, but a process of mechanical imitation. [1]Children acquire their mother tongue one by one by constantly imitating adult words. Listening theory in English teaching is based on this theory. The characteristic of this teaching method is to start from the session, mainly take sentence-based practice, reject the native language in classroom teaching, do not speak grammar rules, and master a certain English through imitation, strengthening and memory. It holds that the mistakes of the learners are intolerable and should be corrected as soon as it appears.
Psycholinguistic epistemic theory of language acquisition was created with the help of the latest research results in Noam Chomsky language theory and cognitive psychology after psychololinguists recognized the many shortcomings of behaviorist psychology. The theory holds that native language acquisition is not a process of mechanical imitation, but a process that embodies the inner creativity of children's thinking, and that the most prominent feature of language ability is its creativity. Children often say that words have certain rules, but not learned from adults. Children's learning words is by gradually forming rules in the mind (equivalent to what we say grammar knowledge), and then according to these rules to understand some previously have not heard sentences or generate new sentences. Thus, cognitive theory focuses on the internal process of children learning language. Cognitive teaching method is developed on the basis of this theory. Foreign language teaching should practice foreign language on the basis of understanding language knowledge and rules, emphasizing meaningful learning and meaningful practice, not only mechanical sentence practice: the four basic skills of language, listening, speaking, reading and writing to develop in an all-round way.

\section{THE PROCESS OF CHILDREN'S MOTHER LANGUAGE ACQUISITION}

In language teaching research, acquisition, is mainly used to describe the process of children mastering the mother language. And the process of mastering the mother tongue is a process of natural formation. In the appropriate language environment, children do not need 
to master their mother language, because it is a process known as acquisition.

Generally speaking, the development of children's language can be divided into pre-language, single-word utterances, two-word utterance, telegraph to infinite sentences and basic maturity stages. Children's language begins with crying, just a pure physiological phenomenon, but as they grow, the meaning of crying is gradually enriched. They represent a certain feeling, emotion of the baby. When hungry, painful, or untimely, the baby often cries out a message to the mother or caregiver. Native language acquisition studies show that about six to eight months after birth, babies can produce some overlapping sounds such as "bababa", they attempt to imitate certain sounds of adults. The baby's sound was not entirely determined by auditory input, with some sounds they had never heard. Bab can emit many different sounds from eight to ten months, some syllables with consonants or vowel variations, occasionally tones like sentences, and pleasing to the ability to use the sounds.

By age one or a half, they walk upright and enter a new stage in language development. They started to speak first words which was the beginning of children true speech. They can generate sentences that contain only one word, which is the single-word utterances. Their words are only words and no grammar, that is, their expression has only two layers of relationship between language and environment, and no connection within the language. The words learned by children at this stage are related to their " here and now " we can find that the semantic category of children is less narrow than their life experience, and the semantic components of words are not as fixed as adults. There are often several verbal meanings of children's words. The same word in different environments, accompanied by different feelings and actions, often have different meanings: "mom" can say that "this is mom", "mom holds me up", "I am hungry" and so on.

For children around the age of two years old, children's language ability begins to be able to output two words, which is called the two-word utterance, and grammar learning also begins from this time. Children's two -word utterance is neither a simple imitation of adult discourse or a random expression combination of words they are familiar with, but the system of meaning they used to express at the time.

"Telegraphy" is another stage in the development of children's language, as they mostly contain only real words, and generally no functional words. Interestingly, children's language development does not seem to go through a three-word utterance, after the two-word utterance, when children construct sentences, they can put three, four, five, or even more words in one sentence, such as "John beat me", "I want apple", etc. Children are about three years old, the vocabulary is close to a thousand words, used by children before the age of five. By the age of five, children have mastered the basic aspects of their mother language, they can understand and can gradually use language in the process of learning language, children's language develops and words become more appropriate.

\section{COMPARISON OF CHILDREN'S NATIVE LANGUAGE ACQUISITION WITH FOREIGN LANGUAGE LEARNING IN ADULTS}

"Acquisition" and "learning" are two meaningful academic concepts, "acquisition" is the process in which young children actively acquire their mother language under non-instructional conditions. "Learning" is the process in which people consciously learn a second language, usually a second language in a teaching environment, after acquiring their native language.

\subsection{Environment}

Environment is a factor in language learning and the biggest difference between native language Acquisition and adult foreign language learning. Children's mother language easily inseparable from a specific language environment, children's mother language learning environment is very superior. Children's mother language acquisition is always in the mother language environment, most of them are in a one-to-one learning environment, in the parents' encouraging language environment, children do not have to worry about whether their mother language is good or not, they have no external pressure or competition. Parents play a positive role in the process of children acquiring their mother language. However, on the contrary, adult foreign language learning is often in a test-oriented foreign language learning environment, in a stressful and competitive learning environment, and is always worried about the use of foreign languages.

When children acquire their mother language, their equal relationship with their parents or other children, in a relaxed and pleasant environment, children are willing to accept and use their mother language. Studies show that learners prefer language learning in equal relationships and are easier to progress. However, in the foreign language learning class, the teacher is the language impart, the organizer, the leader, the students are the learners and the leader, and the relationship between them is not equal. For example, some teachers are very harsh and make students very afraid to answer questions, which is very different from the communication between mother and son in a family environment. In short, the environment learned is very different from the learned environment. 


\subsection{Needs and motivation}

Language is produced in the urgent need of human communication. The enthusiasm and initiative of children's mother language acquisition comes from the need to speak, which is an instinctive need not to transfer from human consciousness. And adult foreign language learning is mostly to improve the level of foreign language, and learning, its initiative and enthusiasm are far less than that of the mother language, which is closely related to urgency. The purpose of children's native language acquisition is to truly communicate using the language learned, and the process of language acquisition is natural, real, and related to the local scene of the time. Children are always happy to maximize the mastered language and respond according to the situation. The purpose of adult foreign language learning is mainly to pass various examinations, and in order to cope with the corresponding tests, the foreign language knowledge must be accurate and grammatical rules. In addition, adults in the process of learning foreign language, language input is based on textbooks selected by teachers or editors, most of which are grammar-compliant nonreal materials, which is unfavorable to the cultivation of their language communication skills. In terms of motivation, native language acquisition is for communication purposes tends more towards "binding motivation", which achieves the purpose of participating in or integrating into the social life of the destination language society by the acquisition of the language. Adult foreign language learners are different from this. Their motivation is mostly "tool motivation", that is, learning a foreign language is to pass a certain exam or obtain a certain profession, not to achieve the purpose of communicating with the destination language society. Due to the different motivation, the acquisition of children's mother language and the effect of adult foreign language learning also differ. Therefore, despite the further efforts of adults, foreign language learners are difficult to achieve their foreign language communication skills regardless of any learning method or to the same extent, affected by the negative migration of their native language.

\subsection{Process}

Children's mother language acquisition is a natural process, while adult foreign language learning is a conscious learning process. Children's acquisition is a direct cognitive process, directly acting in living in a linguistic environment. Because children learn more language environment in their own families, they repeatedly and unconsciously imitate the language of their family (usually their parents) and actively apply to daily communication and dialogue, through this way, they can master their mother language smoothly. Adult foreign language learning is different, it is a conscious learning process. Under the guidance of teachers, learners consciously learn and train the rules of grammar, a process that is much more difficult than children's mother tongue learning. Children acquire their mother language extensively through an unconscious state, and they all pursue fluency in language expression. Adults tend to overemphasize the accuracy of language expression in foreign language learning and whether the language conforms to grammar rules. In addition, how to use language appropriately is the focus of children's mother language acquisition. they pay more attention to the meaning of language expression. The focus of adult foreign language learning is mostly grammar rules, sentence structure and other expressions.

\section{ENLIGHTENMENT FOR ADULT FOREIGN LANGUAGE LEARNING}

Through the comparison of children's mother language acquisition and adult foreign language learning, The above argument demonstrates that adults should find ways to learn language from the way that children learning the native language.

\subsection{Cultivation of an optimistic and confident learning attitude for adults}

The learning attitude of adult foreign language learners has a direct impact on the results of language learning. Practice has proved that an optimistic, confident learning attitude and a pessimistic, hesitant learning attitude will have a completely different development[5]. Language learning should follow the law of language learning, step by step. The biggest enemy of foreign language learning is the learners' pessimistic learning attitude and lack of confidence. Studies shows a widespread lack of confidence among unsuccessful foreign language learners, while optimistic and confident learners tend to make greater progress. In addition, in the teaching process, teachers should strive to cultivate students' self-confidence. Do not interrupt them as much as possible in class, encourage them to speak freely, and let them constantly feel success.

\subsection{Cultivation of adults' awareness of participation}

Children learn their mother language to get such a good effect, because they have a strong sense of subject, take the initiative to express themselves and use language. It is worth noting that in the process of learning their mother language they always participate in language communication activities as equal subjects. When children learn language, adults do not command to children, but talk to them. In this way, both sides are the main body of conversation. Adults have high language levels, and the organizers of the conversation are often children. Children decide the topic, lead to the topic, adults just give and comments or expansion, inject new 
content. Their relationship is equal. Learning in class also requires adult students to have the same sense of subject, fully mobilize their potential, and actively participate in teachers' teaching activities. The establishment of students' subject consciousness largely depends on the teaching atmosphere of the classroom, and the classroom teaching atmosphere is mainly created by teachers. Teachers should respect students in teaching, and pay attention to establishing and maintaining an equal relationship with students. In a relaxed and harmonious teaching atmosphere, teachers are easy to see the potential and active spirit of students, and students also have the opportunity to give full play to their enthusiasm and creativity.

\subsection{Cultivation of the spirit of adults to practice foreign languages}

Language has creative essential characteristics, and the ultimate goal of foreign language learning is to communicate learned. Practice has proved that students who are active and brave to speak in class are easy to make progress, while those who dare not try and are afraid of making mistakes are difficult to learn their foreign language well. Successful language learners usually have a strong desire to communicate, and they are not afraid to make mistakes in language practice before they succeed. And from the long-term trend, the spirit of daring to use a foreign language for practice is conducive to the learning of the destination language. Therefore, teachers should encourage students to try bravely in class, consciously, actively, and creatively use the language knowledge they have learned. It is impossible that a learner never makes a language mistake. Making a mistake is not a bad thing, it can deepen students' understanding of a certain language phenomenon. Therefore, teachers should provide students with opportunities for language practice.

\subsection{Emphasis on the "internalization" of language rules}

Psycholinguists observe studies found that children learn words not only by imitation and mechanical repetition, but "internalize" language rules through constant contact with language materials, forming implicit rules, and "creatively " uses language. This seems to be the "working principle" that the human brain deals with new language materials. This principle can be borrowed into adult Foreign language teaching. The brain of children is not fully mature in the language learning stage, and its so-called language rules. internalization " process can be said to be unconscious. Moreover, the adult intelligence and thinking ability have been quite developed, people can consciously, consciously to understand the language materials, summarize the language rules. Adults are much stronger than children in this respect. To make full use of this advantage of adults, people can read more Foreign language, so that foreign language learners can summarize the rules of foreign language through reading a large number of materials, and cultivate the ability of foreign language independent learning. Other language phenomena in foreign languages such as grammar, sentence pattern, idioms and others can be familiar, mastered and utilized by the "internalization" of this language rule. One of the tasks of foreign language teachers is to provide as much appropriate foreign language materials as possible for adult learners to listen, speak, read, write and sum up certain language rules to learn further.

\subsection{Scientific way of dealing with mistakes}

In the language of communication, as long as it does not affect the expression of the original intention,it does not need to be corrected on the spot, but afterwards the main problem of the learners can be pointed out [6]

It is the language ability mistakes, they reflect the learner's language ability problems, learners really do not know what to say. If the effect teacher can help to point out in time, the learner's mood will not be affected. There is also a kind of error is the language use error, it can be said to be an error. For example, when communicating in foreign language, the noun plural is used singular, when writing, the first letter is not capital. All these were mastered by the learner, and mere negligence made similar errors in some places, and therefore need not be corrected on the spot. Because this will hurt the confidence of learners, learners will be afraid of making mistakes and dare not speak, start to write. But they cannot let it go. Especially when training the learners language ability, teachers should find out the typical and universal language mistakes, and correct at any time, which is completely necessary.

\section{CONCULUSION}

The above briefly discusses the enlightenment of adult Foreign language teaching from the perspective of psycholinguistics. In fact, as a marginal subject attracting more and more attention, psycholinguistics in the study of children's mother language acquisition can be used for adult Foreign language teaching far more than the few listed above. As long as foreign language teachers often study books in psychological linguistics and pay close attention to the latest results of psycholinguistics research, they will certainly find more new views and theories that can be used for adult Foreign language teaching.

\section{REFERENCES}

[1] Wang Hongmei. From children's mother tongue, I taught outside school. 
[2] Chen Ling-Mother language learned foreign language teaching.

[3] Du Yichun. New Psycholinguistic.

[4] Liu Jixin et al. On the relationship between emotional factors and adult foreign language learning.
[5] Wang Cairen. English Teaching and Communication Theory.

[6] Zhong Mao. Differences between native language acquisition and foreign language learning. 